\title{
Iniciativas e ações públicas para mitigação da ilha de calor urbana em cidades médias: o caso de Jacareí-SP
}

Public initiatives and actions to mitigate urban heat islands in mid-size cities:

the case of Jacarei-SP

Initiatives et actions publiques pour atténuer les îlots de chaleur urbaine dans

les villes intermédiaires: le cas de Jacareí-SP

Iniciativas y acciones públicas para mitigar las islas del calor urbano en

ciudades medias: el caso de Jacareí-SP

Neli Aparecida De Mello-Théry (in memoriam), Andrea Cavicchioli e Eduardo de Lima Caldas

\section{(2) OpenEdition}

\section{Journals}

Edição electrónica

URL: https://journals.openedition.org/espacoeconomia/18780

DOI: 10.4000/espacoeconomia.18780

ISSN: 2317-7837

Editora

Núcleo de Pesquisa Espaço \& Economia

\section{Refêrencia eletrónica}

Neli Aparecida De Mello-Théry (in memoriam), Andrea Cavicchioli e Eduardo de Lima Caldas,

«Iniciativas e ações públicas para mitigação da ilha de calor urbana em cidades médias: o caso de Jacareí-SP », Espaço e Economia [Online], 21 | 2021, posto online no dia 30 junho 2021, consultado o 17 julho 2021. URL: http://journals.openedition.org/espacoeconomia/18780 ; DOI: https://doi.org/ 10.4000/espacoeconomia.18780

Este documento foi criado de forma automática no dia 17 julho 2021.

\section{cc) (†)}

Espaço e Economia - Revista brasileira de geografia econômica est mise à disposition selon les termes de la licence Creative Commons Attribution - Pas d'Utilisation Commerciale - Partage dans les Mêmes Conditions 4.0 International. 


\section{Iniciativas e ações públicas para mitigação da ilha de calor urbana em cidades médias: o caso de Jacareí-SP}

Public initiatives and actions to mitigate urban heat islands in mid-size cities:

the case of Jacarei-SP

Initiatives et actions publiques pour atténuer les îlots de chaleur urbaine dans

les villes intermédiaires: le cas de Jacareí-SP

Iniciativas y acciones públicas para mitigar las islas del calor urbano en

ciudades medias: el caso de Jacareí-SP

Neli Aparecida De Mello-Théry (in memoriam), Andrea Cavicchioli e Eduardo de Lima Caldas

\section{Introdução}

1 Atualmente, cerca de $85 \%$ da população brasileira vive em espaços urbanizados (IBGE, 2017), sejam cidades metropolitanas ou do interior, cidades grandes, médias ou pequenas. Nas regiões metropolitanas, definidas pelas Assembleias Legislativas de cada estado federado, as áreas metropolitanas, com seus municípios grandes, médios e pequenos, são de alta densidade de pessoas e atividades humanas, frequentemente desordenadas e, consequentemente, sujeitas a fortes alterações ambientais, nas quais não se exclui a formação da ilha de calor urbana. Algumas metrópoles começam a implantar políticas (ou mesmo ações) de mitigação ou de adaptação às mudanças climáticas, embora nem sempre decorrentes da percepção social sobre o fenômeno. Os estudos sobre a formação de ilhas de calor urbana são identificados desde os anos 90 , tanto diagnósticos como prospectivos, incluindo, portanto, tanto os efeitos atuais como 
os futuros das mudanças climáticas. No Brasil, para as cidades de porte médio (100.000 a 500.000 habitantes), há pouca pesquisa sobre as diversas consequências da formação e do aumento das ilhas de calor urbana (AMORIM et. al, 2009; PORANGABA et. al, 2017; AMORIM et. al, 202) e os gestores de políticas públicas ainda se servem pouco de tais prospectivas para o planejamento e a gestão das cidades.

2 Para suprir parte dessa insuficiência de estudos sobre políticas de mudanças climáticas em municípios de médio porte, este trabalho analisa o município de Jacareí, no estado de São Paulo (sudeste do país), localizado a $80 \mathrm{~km}$ da capital e parte de uma região metropolitana em desenvolvimento no eixo rodoviário São Paulo-Rio (Vale do Paraíba e Litoral Norte). Jacareí possui uma área de $464.272 \mathrm{~km}^{2}$ e uma população de 230.000 habitantes, em sua quase totalidade concentrados no espaço urbano.

Dentre os objetivos deste trabalho destacamos:

4 (1) levantar dados e gerar informações sobre o clima no município de Jacareí, por meio da instalação de sensores de temperatura;

(2) analisar como (e se) os gestores públicos municipais de Jacareí entendem o clima, suas especificidades, a ocorrência da ilha de calor urbana e seus impactos;

6 (3) levantar, sistematizar e analisar os instrumentos de políticas públicas, instituídos, que estão direta e indiretamente relacionados com políticas de mudanças climáticas tanto de mitigação quando de adaptação.

70 presente texto apresenta resultados parciais da pesquisa e cumpre alguns de seus objetivos, em especial, a análise de dados gerados no primeiro ano do projeto assim como a análise das ações e instrumentos disponíveis para a gestão urbana e está estruturado em duas seções destinadas à explicitação da conjuntura regional e local, em seguida a análise dos dados de temperatura, às quais se seguem análises e conclusões a respeito das relações com as ações municipais empreendidas em prol da minimização de temperaturas por meio da revegetação de ruas e avenidas.

\section{Arcabouço Teórico-Metodológico}

8 Do ponto de vista metodológico, apresentaremos os dados de temperatura do ar da superfície e de umidade relativa obtidos durante a primeira etapa de um programa de monitoramento realizado no território de Jacareí, entre junho e dezembro de 2019, nas áreas urbana, periurbana e rural do município. Três estações meteorológicas equipadas com registradores de dados de temperatura e umidade relativa possibilitam traçar uma estrutura preliminar da extensão e da variabilidade temporal da ilha de calor urbana. A partir desses dados meteorológicos e da leitura de documentos oficiais tais como o programa de governo (registrado na Justiça Eleitoral no momento das eleições municipais 2016 e 2020), do Plano Plurianual (2017), dos orçamentos públicos municipais anuais, de programas e projetos específicos constantes ou não nos referidos documentos e que estejam relacionados com a questão climática, pretende-se compreender a efetividade da política municipal.

9 Em termos teóricos analíticos, três noções estão na base de nossas reflexões e abordagem sobre o clima: ilha de calor urbana, percepção dos atores e instrumentos da ação pública (MELLO-THÉRY et. al, 2020). 
10 Sobre as ilhas de calor, Monteiro (1976) propõe seu entendimento como um sistema sistema clima urbano (SCU). Para ele, nos estudos geográficos sobre os climas das cidades é preciso considerar três canais de percepção que envolvem o conforto térmico, a qualidade do ar e o impacto meteorológico. Esse sistema refere-se à visão integrada entre as características físicas das cidades e as formas de ocupação do espaço e do adensamento típico dos ambientes urbano. Apesar do tempo passado, a proposta metodológica continua presente nas pesquisas atuais no Brasil, ainda que haja o aperfeiçoamento nas técnicas ligadas à aquisição dos elementos do clima, conforme indicam Amorim e Ugeda Junior (2016). Lembram esses autores que Monteiro também considerava a questão do entrelaçamento de escalas geográficas, indicando que no clima urbano esses fatores dependerão, por exemplo, da extensão da cidade e de sua posição no relevo.

11 Mendonça (2012) ao tratar da "escola brasileira de climatologia urbana" afirma que esta se caracteriza por enquadrar os estudos de clima na teoria da complexidade e reforça a necessidade da adoção de premissas holísticas. Para ele, a Rede Clima no Brasil que se integra a de outros países, valoriza as muitas interfaces entre ciências físicas e naturais e ciências humanas e sociais aplicadas como novo campo de produção de conhecimentos e constitui-se em importante frente para pesquisar as políticas de adaptação às mudanças climáticas.

12 O conceito de ilha de calor urbana expressa um sintoma do clima urbano e pode ser obtida a partir de medidas de diferença de temperatura. Tal sintoma indica um dos maiores problemas ambientais do século XXI, junto a outros fenômenos associados ou resultantes também das mudanças climáticas façam parte do sistema clima urbano, como a poluição atmosférica e as inundações.

13 As ilhas de calor são um fenômeno influenciado pela ação humana. Oke (1987) indicou que a temperatura do ar na cidade é maior onde as atividades humanas são mais intensas, apontando que o centro urbano tem maiores temperaturas, que diminuiriam nos limites com as áreas urbanas periféricas e no limite entre o urbano e o rural.

14 Do ponto de vista geográfico, Lombardo (1985) vinculou as temperaturas com a concentração de poluentes. Ao analisar a metrópole de São Paulo, em sua tese, mostrou que a área urbanizada altera o balanço de energia, gerando "bolsões" de calor, denominadas "ilhas de calor". Essas ilhas de calor apresentam características comuns: forma, intensidade e localização do seu núcleo mais quente. Seu padrão espacial é influenciado pelos atributos locais de superfície e topografia. De tal modo, parques, corpos hídricos e adensamento das áreas construídas geram efeitos sobre a temperatura e umidade. $O$ padrão temporal se estabelece pelas diferenças entre dia e noite. Esses fenômenos refletem na qualidade de vida da população local tanto quanto as degradações ambientais e as mudanças substanciais advindas da urbanização. Esses fatores são importantes e devem ser considerados na gestão ambiental urbana.

É a partir dessa abordagem holística que se recupera também a noção de percepção das mudanças climáticas. A percepção é objeto de estudo de diversos campos do conhecimento, iniciados na Psicologia no século XIX. No decorrer do século XX, Skinner, Piaget, Merleau-Pointy tornaram-se ícones na área comportamental e Yi-Fu Tuan, Lynch e UNESCO foram pioneiros em adotar a noção de "percepção" na Geografia e na área ambiental. Contudo, percepção das mudanças climáticas é uma abordagem pouco usada na climatologia e visa analisar e compreender o clima a partir da percepção humana. Ressalta a sensibilidade e a subjetividade do homem como um meio 
para compreender a realidade e, sobretudo, como tais percepções podem ser indutoras de mudanças.

Deve-se a J. Pérard (1997) os primeiros usos dessa noção de percepção ao considerar que, para lutar contra os riscos climáticos e aperfeiçoar a gestão dos recursos do clima, duas abordagens científicas eram essenciais e que embora distintas, elas se complementavam. Para ela, a análise climatológica somente de modelos físicos tornarase insuficiente por não considerar os fatores de ordem humana. Não basta, portanto, a produção de dados climáticos, a análise complexa dos referidos dados, a produção de conhecimento e a geração de informação. Esse conhecimento prévio pode, em seguida, ser confrontado com as percepções dos atores locais. Assim, percepção, para os propósitos deste trabalho, é vista como fenômeno subjetivo e muitas vezes amparado pela difusão excessiva do assunto por grupos de atores totalmente distintos e pode ser gerada quando os níveis de influência são mais elevados.

Quanto aos instrumentos, trata-se de uma noção usada amplamente no campo da ação pública, confluência entre a ciência política e a análise das organizações. Os instrumentos da ação pública são dispositivos governamentais expressos na forma da Lei, de orçamento, da instituição de cargos e autoridades, de procedimentos administrativos que materializam projetos governamentais e, portanto, as representações, as ideias, as visões de mundo dos governantes e dos atores sociais que interagem e influenciam os governos nas diversas arenas e fóruns públicos. Hood (1986) propôs uma tipologia simples, dizendo que todos os instrumentos de políticas públicas baseiam-se no acrônimo "NATO": informação (Nodalidade), poderes legais (Autoridade), recursos financeiros (Tesouro) e recursos organizacionais formais (Organização). Outras tipologias surgiram desde então: Salamon (2002) identifica 14 tipos de instrumentos. Etzioni (1972) identifica três tipos de instrumentos: "carrots, sticks and sermons" (cenouras, chicotes e sermões). Recentemente Lascoumes e Les Galès (2012) analisam os instrumentos como processos sociais instituídos e materizalização de ideias e crenças sociais (CALDAS e MASSARDIER, 2020).

Para os propósitos deste trabalho, instrumentos são meios para atingir o fim de uma política e visam atender determinados objetivos, portanto, expressam interesses, ideias e prioridades da sociedade e dos governos. É importante ter em mente sua finalidade política visto que em uma análise exclusivamente técnica, a institucionalização dos instrumentos é "naturalizada" e tende-se a crer em sua "neutralidade". Assim considerando, os instrumentos direcionam a ação e produzem impactos na sociedade, modificando, influenciando e transformando comportamentos humanos.

\section{Conjuntura Regional e Local}

19 Jacareí faz parte da região metropolitana do Vale do Paraíba e Litoral Norte (Figura 1). Criada em 2012 pela lei complementar 1.166, com 39 municípios, em 2016 contava com 2,5 milhões de pessoas representando cerca de 5,5\% da população do Estado de São Paulo. É uma das mais dinâmicas e também mais díspares regiões do Estado de São Paulo, bastante diferenciada internamente pelas atividades econômicas, respondeu por aproximadamente 5\% do PIB estadual, segundo a Seade em 2016. Localiza-se entre as duas macrometrópoles brasileiras, São Paulo e Rio de Janeiro, simultaneamente contribuindo e se beneficiando dessa condição. 
20 A produção industrial é muito desenvolvida com predomínio dos setores automobilístico, aeronáutico, aeroespacial e bélico no eixo da Rodovia Presidente Dutra. No Litoral Norte destacam-se também as atividades portuárias e petroleiras enquanto o turismo ocorre nas Serras da Mantiqueira, da Bocaina e do Mar, no litoral e cidades históricas em razão importantes patrimônios ambientais de relevância nacional e pelas fazendas de valor histórico e arquitetônico.

21 A região metropolitana é caracterizada por um clima subtropical úmido (Köppen Cfa), com temperatura média anual entre 19 e $21^{\circ} \mathrm{C}$. Porém, estudo recente (Ynoue, 2014) projeta para a mesma um aumento de $3^{\circ} \mathrm{C}$, mesmo em um cenário de estabilização para as emissões de gases de efeito estufa (A1B).

$22 \mathrm{Na}$ atualidade, cumprindo as obrigatoriedades do Estatuto da Metrópole (aprovado em 2015) as instituições regionais preparam a elaboração do Plano de Desenvolvimento Urbano Integrado (PDUI). É o momento de serem definidos os fundamentos desse planejamento e das formas de participação social.

Com objetivos de alavancar o desenvolvimento regional, desde os anos 1930, esta região tem sido objeto de planejamentos públicos e privados. Destaque para os principais: nos anos 1970, a presença da rodovia Presidente Dutra (construída entre os anos 1940 e 1960) promove mudança de foco econômico e de área, transformando em industrial o eixo São Paulo - Rio, atraindo não apenas migrantes, mas novas atividades econômicas, incluindo o complexo aeroespacial em São José dos Campos. Desde então, outros planos foram realizados na expectativa de estabelecer uma política de desenvolvimento regional: nos anos 1990, o Macrozoneamento do Vale do Paraíba e do Litoral Norte de São Paulo e o da Bacia do rio Paraíba do Sul, no âmbito da Política Nacional de Recursos Hídricos. Nos anos 2000, a partir das leis nacional (lei 7.661/1988) e estadual (lei $10.019 / 1998)$ relativas aos planos de gerenciamento costeiro, instituiu-se o zoneamento ecológico-econômico do Litoral Norte. O plano metropolitano do Vale do Paraíba e Litoral Norte está sendo desenvolvido sob a responsabilidade da AgemVale (Agencia Metropolitana do Vale do Paraíba) e deverá ser concluído durante o ano de 2020.

A área metropolitana não pode representar somente a complementaridade do Plano de Ação da Macrometropole Paulista (PAM) (EMPLASA, 2014) e, portanto, não pode ser pensada apenas como uma peça do quebra-cabeças metropolitano, sem levar em consideração as condicionantes regionais e locais (GOMES, RESCHILIAN e UEHARA, 2018). No entanto, não se deve deixar de constatar que os Vetores do Vale do Paraíba e de Desenvolvimento Perimetral da Macrometrópole, ressaltados no Plano de Ação Macrometropolitano (PAM), demonstram uma estruturação espacial urbana vinculada a São Paulo, embora não dependente. 
Figura 1 - Localização de Jacareí no estado de São Paulo

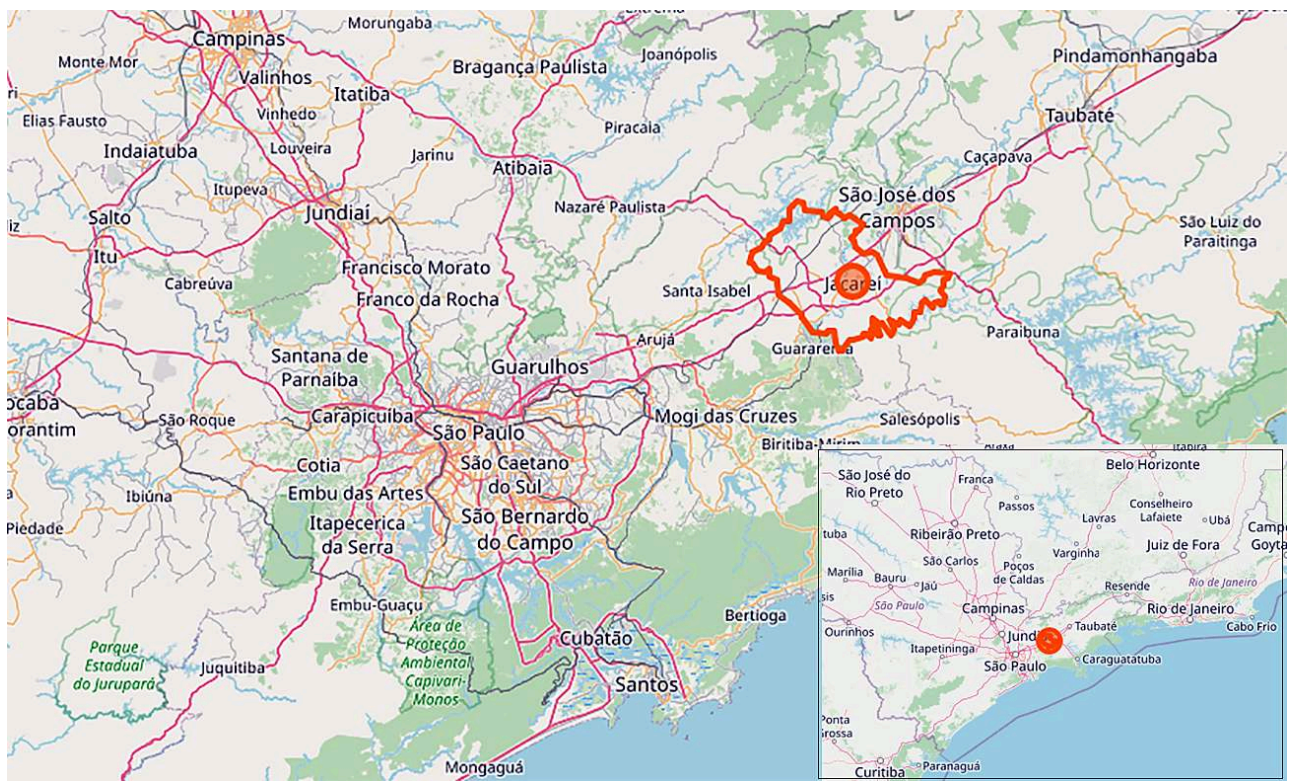

FONTE:OPENSTREETMAP 
Incluía, desta maneira, os preceitos anteriores (lei 4549/2001) direcionados ao plantio, supressão, poda, transporte e derrubada de espécies vegetais. Em 2008, nova lei (5269/2008) altera-a em alguns pontos. A lei complementar cria também o Conselho Municipal de Habitação e Desenvolvimento Urbano.

Em 2016, o Programa de Governo do prefeito eleito, Izaias José Santana, não tratava da questão climática de forma explícita, embora tivesse nele questões implícitas tais como:

no eixo mobilidade o compromisso de constituir "circuitos cicloviários nos bairros" e "ampliar a malha de ciclovia dos atuais $1,81 \mathrm{Km}$ para $18 \mathrm{Km}$, interligando a atual ciclovia aos prédios públicos e conectando diversos bairros". É verdade que não faz menção à possibilidade de instituir corredores de ônibus e tampouco uma "ecofrota" ainda que experimental;

nos eixos meio ambiente e bem viver e sustentabilidade há uma série de compromissos como "ampliar o Programa Municipal de Coleta Seletiva", "fortalecer um circuito de produtores familiares com base agroecológica, "implantar um Programa Municipal de Agricultura Urbana", "criar o Programa de Praças e Parques Públicos" e a criação de um "Plano Municipal de Arborização como ação prioritária".

Apesar dessas ações mitigatórias e adaptativas, não se usa a linguagem diretamente relacionada com o enfrentamento da questão climática. Trata-se, portanto, no mínimo, de uma ausência de percepção da relevância da questão. A "porta de entrada" do debate climático não é o enfrentamento da questão climática.

Atualmente o município possui um Conselho de Desenvolvimento e tem uma nova proposição para a atualização do Plano Diretor, embora tentativas tenham ocorrido na Câmara municipal em 2013, 2018 e 2019. Em janeiro de 2020 a prefeitura retoma o processo de revisão do Plano Diretor, estabelecendo um Conselho Gestor, com a participação da sociedade civil (movimentos populares, entidades de classe, empresas ou entidades profissionais, entidades acadêmicas e de pesquisa e organização da sociedade civil que desenvolva projetos sociais com finalidade pública). Foi criado um grupo de trabalho (GT) visando dar-lhe suporte. A Universidade do Vale do Paraíba foi contratada para dar suporte técnico. Todo o processo de revisão vai seguir os critérios acordados pela Prefeitura Municipal de Jacareí em conjunto com a Defensoria Pública e Ministério Público.

36 A lei sobre uso, ocupação e urbanização do solo municipal, aprovada em 2005, incorpora todos os elementos do plano diretor de ordenamento territorial e as diretrizes do seu macrozoneamento. Os parâmetros urbanísticos definidos nesta lei são taxa de permeabilidade, coeficiente e aproveitamento, recuo, gabarito, taxa de ocupação. Ressaltamos a taxa de permeabilidade que visa contribuir para a melhoria do ambiente natural e construído, bem como a temperatura e umidade do ar, servindo-se para tal, do plantio de vegetação de pequeno, médio e grande porte, entre outros.

Existem poucas avaliações sobre o andamento dos compromissos assumidos em campanha e outras ações, tais como o programa para o sistema de áreas verdes e arborização da cidade, dentre as quais Faria et al. (2007) que utilizaram o Manual Técnico de Arborização Urbana da Secretaria do Verde e Meio Ambiente da prefeitura de São Paulo (2006) para a análise da arborização em 6 vias urbanas e concluíram que uma pequena quantidade está em bom estado e indicam a necessidade de substituir algumas árvores e de introduzir novos plantios na cidade. Contudo, os autores não analisaram se a quantidade de vegetação é suficiente para a melhoria do clima, seja do 
ponto de vista da captação de carbono seja do ponto de vista adaptativo, melhorando a permeabilidade do solo, seja do ponto de vista da sensação térmica e da redução de "ilhas de calor".

\section{Análise de Medidas de Temperaturas}

38 As estações meteorológicas foram instaladas em três pontos fixos, contemplando um ambiente urbano (jardim do Museu de Antropologia do Vale do Paraiba), um periurbano (parque do Viveiro Urbano) e um rural (jardim da escola rural EMEF Presbitero Mábito Shoji).

Quadro 1: Coordenadas geográficas das estações de monitoramento

\begin{tabular}{|c|c|c|c|c|}
\hline Estação de monitoramento & Latitude & Longitude & Altitude & $\begin{array}{l}\text { Distância do ponto } \\
\text { central }\end{array}$ \\
\hline $\begin{array}{l}\text { Jardim do Museu de Antropologia do } \\
\text { Vale do Paraíba }\end{array}$ & $\begin{array}{l}23^{\circ} 18^{\prime} 22.81 \text { 廆 } \\
\mathrm{S}\end{array}$ & $\begin{array}{l}45^{\circ} 58^{\prime} 22.15 \text { 區 } \\
W\end{array}$ & $570 \mathrm{~m}$ & - \\
\hline Parque do Viveiro Urbano & $\begin{array}{l}23^{\circ} 18^{\prime} 52.74 \text { 熙 } \\
\mathrm{S}\end{array}$ & $45^{\circ} 58^{\prime} 1.59$ 喝 $\mathrm{E}$ & $600 \mathrm{~m}$ & $1090 \mathrm{~m}$ \\
\hline $\begin{array}{l}\text { Jardim da escola rural EMEF } \\
\text { Presbítero Mábito Shoji }\end{array}$ & $\begin{array}{l}23^{\circ} 18^{\prime} 25.90 \text { 医 } \\
\mathrm{S}\end{array}$ & $46^{\circ} 2^{\prime} 20.85$ 厚2 $\mathrm{F}$ & $640 \mathrm{~m}$ & $6700 \mathrm{~m}$ \\
\hline
\end{tabular}

FONTE: ELABORAÇÃO PRÓPRIA.

39 Cada estação foi equipada com um datalogger de temperatura e umidade relativa, modelo U10-003 (Onset, EUA) apresentando uma margem de erro de $0,5{ }^{\circ} \mathrm{C}$ e $3,5 \%$ respectivamente. Os sensores foram colocados em abrigos meteorológicos que, por sua vez, foram montados em suportes a uma altura de $2 \mathrm{~m}$. A precisão de todos os sensores foi verificada antes do início do monitoramento. As series de dados, coletadas em intervalos horários entre 14/06/2019 e 20/02/2020, foram processadas em tabelas do Excel.

A ilha de calor presente na área urbana de Jacareí foi caracterizada de maneira preliminar, neste trabalho, por medições de temperatura em um intervalo de tempo

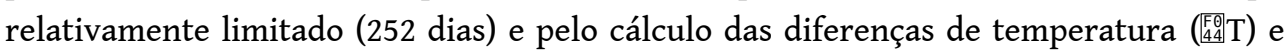
umidade relativa ([4⿻ $\mathrm{FH}$ ) entre o ponto urbano de monitoramento e os pontos periurbano e rural. Os parâmetros considerados foram os valores médios obtidos em todo o período de monitoramento, bem como os períodos correspondentes aos meses de agosto (mediamente mais frio) e janeiro (mediamente mais quente). Essa avaliação, que inclui as médias dos valores mínimos e máximos diários nos mesmos intervalos de tempo, é mostrada nos gráficos da figura 3.

Figura 2: Localização da estação de monitoramento no Parque do Viveiro Urbano, área periurbana de Jacareí 


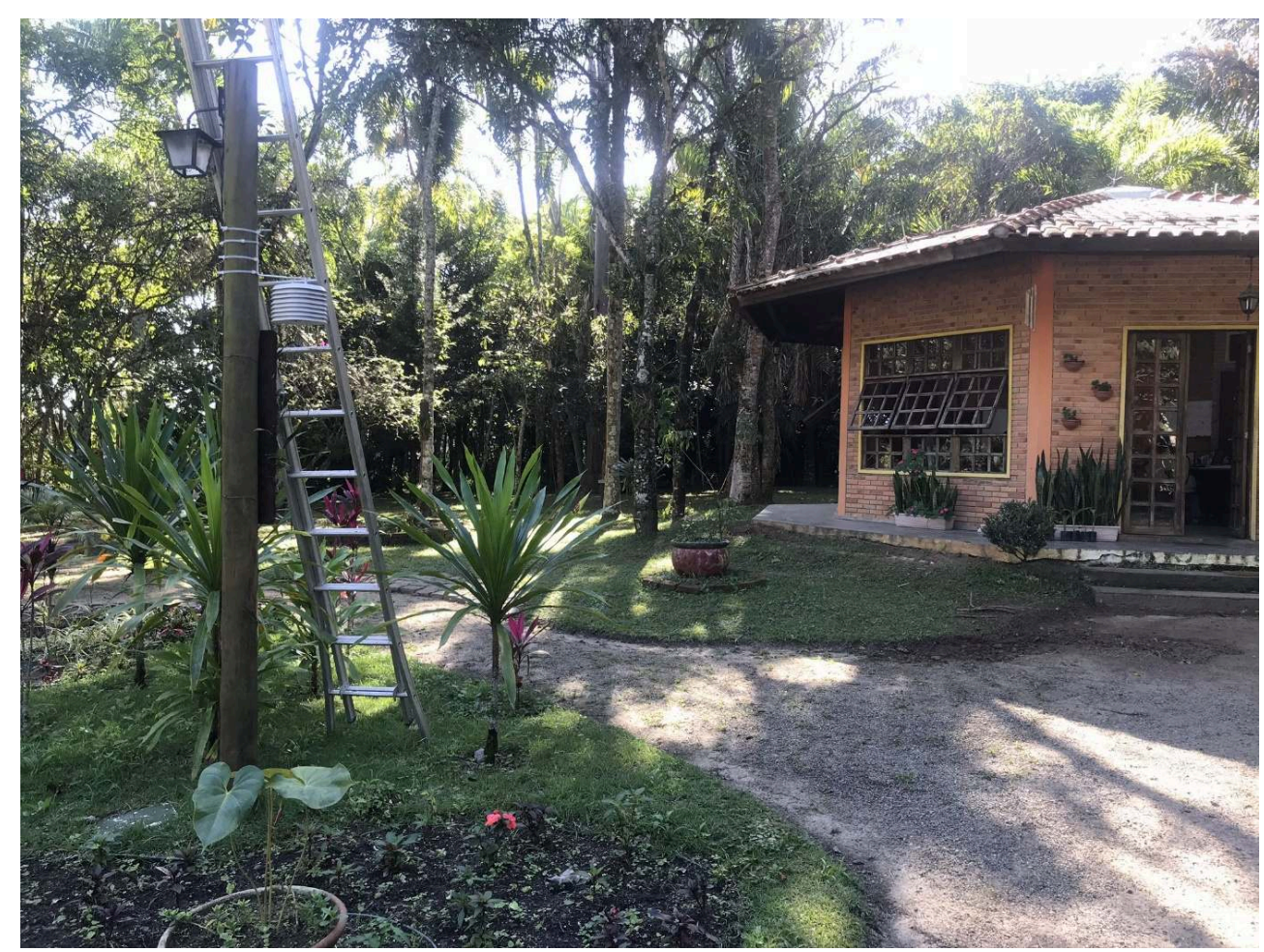

FOTO ANDREA CAVICCHIOLI, 2019.

41 Em relação à temperatura (figura $3 \mathrm{~A}-\mathrm{C}$ ) todas as observações apontam para um ${ }_{44}^{[\mathrm{F}} \mathrm{T}$ positivo, portanto com temperaturas mais altas no centro urbano da cidade em comparação com os outros dois pontos, com diferenças médias de $1,1^{\circ} \mathrm{C}$ no caso da área rural e $1,6^{\circ} \mathrm{C}$ no caso do parque na região periurbana. Em todos os casos, as diferenças entre valores mínimos de temperatura são mais acentuadas do que aquelas entre os valores máximos, o que indica que fora do centro urbano a queda noturna da temperatura é sempre mais alta do que no centro da cidade. Esse efeito é mais expressivo dentro do parque urbano $\left(\left[\begin{array}{l}{[49} \\ 4\end{array} \mathrm{~T}=3,6^{\circ} \mathrm{C}\right)\right.$, talvez devido ao resfriamento associado ao processo endotérmico de transpiração e evaporação da água em local rico em vegetação que, portanto, atua como ilha de frescor à noite.

Por outro lado, no caso de temperaturas máximas, o maior aumento de temperatura urbana ocorre em relação ao ponto rural; com um ${ }_{44}^{\text {Fit }} \mathrm{T}$ médio de $2,1^{\circ} \mathrm{C}$ que sobe para $2,3^{\circ} \mathrm{C}$ no mês de janeiro. $\mathrm{O}$ parque periurbano, embora tenha um grau reduzido de

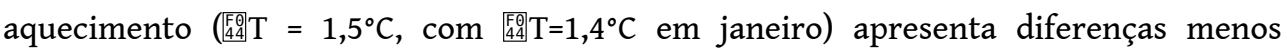
expressivas em relação à área rural, talvez devido ao efeito de proximidade com o centro urbanizado. Deve-se notar, no entanto, que foram observados episódios instantâneos de 䐉 $\mathrm{T}$ de até $8,2^{\circ} \mathrm{C}$ e que diferenças instantâneas maiores tendem a ocorrer pela manhã devido a um aumento mais rapido da temperatura urbana nesta fase, uma observação que ainda requer investigação, mas que pode depender do tráfego intenso de veículos.

43 Em relação aos valores de umidade relativa registrados no período considerado (figura 3D-F), todas as observações apontam para ${ }_{44}^{[F} \mathrm{RH}$ negativo, portanto, com uma umidade relativa sistematicamente mais baixa no centro urbano da cidade em comparação nos dois pontos, com diferenças médias de $-5 \%$ em comparação com o ambiente rural e -9\% em comparação com o parque na região periurbana. No entanto, no contexto climático 
geral, a região é caracterizada por uma umidade relativa média relativamente alta (por exemplo, a estação metereológica mais próxima indica uma RH média de cerca de $75 \%$ no mesmo periodo coberto por esta pesquisa) e, por esse motivo, é mais relevante focar na RH mínima, quando essa quantidade atinge valores de até $15 \%$, como foi o caso na tarde de 18/09/2019.

Figura 3. Diferenças entre as temperaturas ( $\left(\mathbb{F}_{44} \mathrm{~T}, \mathrm{~A}-\mathrm{C}\right)$ e umidade relativa $\left({ }_{44}^{\mathrm{F}} \mathrm{RH}, \mathrm{D}-\mathrm{F}\right)$ medidas no centro urbano de Jacareí em relação ao ponto rural e ao parque periurbano, durante diferentes períodos
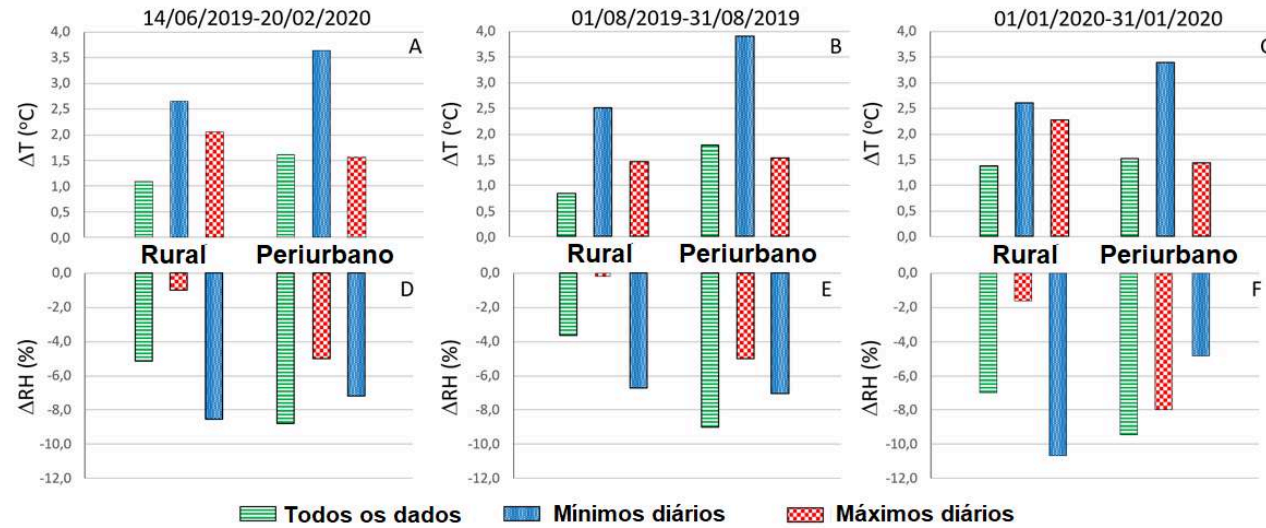

FONTE : ELABORAÇÃO PRÓPRIA.

Em particular, as barras azuis na figura 3E (diferenças médias entre a RH minima em agosto de 2019) indicam baixa umidade relativa, cerca de $7 \%$ no centro da região urbana, em comparação com o ambiente rural. Este efeito é neutralizado dentro do parque periurbano, onde os valores médios mínimos de RH são próximos aos das áreas rurais. Note-se que esse efeito na área arborizada resulta da contribuição térmica (temperaturas mais baixas) e da variação do conteúdo absoluto de vapor de água no ar: por exemplo, com base em dados horários de agosto e setembro, calculou-se um excedente médio de $10 \%$ da quantidade de vapor d'água no ar $(\mathrm{g} / \mathrm{kg})$ do parque periurbano, em comparação com o centro de Jacareí (excedente que permanece se a média é aplicada somente aos casos de episódio de $\mathrm{HR}<40 \%$ ).

A ilha de calor urbana ocorre na ordem de 1,5 a $2,5^{\circ} \mathrm{C}$ (dependendo do período e da série de dados considerados), sendo mais evidente na diferença entre as temperaturas mínimas do centro urbano e da área rural. o parque localizado na região periurbana da cidade suaviza o efeito da ilha de calor, tanto com uma queda nas temperaturas mínimas abaixo do nível rural, quanto com um aumento (em média 7\%) dos valores de umidade relativa em episódios de alta secura do ar no inverno.

Para esta fase da pesquisa, apesar da quantidade limitada de equipamento, pode-se evidenciar que o processo de urbanização altera o clima local.

\section{Análise e Discussão}

Mesmo o tema não estando explícito nas políticas e seus desdobramentos, quando no encontro com o prefeito municipal, é clara sua percepção quanto as relações entre bairros mais ou menos vegetados, mais ou menos próximos à rodovia, em sítios geográficos distintos. Ele (o prefeito municipal) elenca os bairros Parque Califórnia e 
Jardim Califórnia e Vila Branca que estão no mesmo platô, mas possuem características sociais muito distintas sugerindo a ampliação das medições. Ressalta, assim que a variável relevo fica isolada e a variável social passa a ter maior importância para explicar eventual mudança de parâmetros climáticos. Por outro lado, ressaltou o fator adensamento e área verde em dois outros bairros, Cidade Salvador e Jardim Paraíso, ambos bairros localizados muito próximos. 0 primeiro, muito adensado e sem área verde e o segundo, menos adensado e com mais área verde.

A percepção das temperaturas mais elevadas ou mais baixas que o prefeito tem de sua cidade ilustra uma relação entre clima e as distintas configurações sociogeográficas de cada bairro.

O momento atual de revisão do plano diretor municipal (PD) e de elaboração do plano metropolitano (PDUI) é bastante favorável para que questões relacionadas com as mudanças climáticas possam ser claramente incluídas nos mesmos, simultaneamente com a valorização das condicionantes locais e regionais. É o momento de utilizar os instrumentos da ação pública, definindo como objetivos a melhoria das condições de vida de cada cidade com o aumento de áreas vegetadas no interior dos bairros, dando prioridade àqueles para os quais haja dados climáticos.

Dois aspectos precisam ser ressaltados: no PDUI, as características da dinâmica regional devem ser levadas em consideração sem se desprezar as situações intra-urbanas e subregionais, promovendo as relações entre o intra-urbano, o urbano e o regional. Tanto os Conselhos locais e regionais já citados (Consad e Codivar) quanto o Consórcio de Desenvolvimento Integrado do Vale do Paraíba Litoral Norte e Mantiqueira (CODIVAP) poderão colocar nessa esfera de decisão política e articular os distintos campos de forças, obrigando seus membros a pensar nas múltiplas escalas do planejamento e das decisões, município, região e Estado.

O segundo aspecto, a revisão do Plano Diretor (PD), para o qual Jacareí criou um grupo de trabalho, tem uma universidade que dará o suporte técnico e conta com um Conselho Gestor. Lembramos que o município possui também um Conselho de Desenvolvimento. Tais instrumentos da ação pública precisam trabalhar com a complexidade do planejamento intra-urbano em cidades de regiões metropolitanas, pois, ao mesmo tempo em que se pensa o futuro da cidade, há que também refletir sobre o que é e o que se quer para a região em longo prazo.

\section{Conclusão}

52 Este trabalho apresentou resultados preliminares sobre a ilha de calor urbano no município de Jacareí e a percepção de sua ocorrência por parte do prefeito municipal. Este trabalho também apresentou um conjunto de instrumentos de políticas públicas, predominantemente Leis mas também os programa de governo mais recente registrado na Justiça Eleitoral.

53 A partir desses três elementos foi possível observar que apesar da percepção do Prefeito Municipal e da evidência da ilha de calor nas regiões mais urbanizadas por um lado, os instrumentos de políticas públicas ou desconsideram a questão climáticas ou incidem sobre ela de forma indireta e sem indicativo discursivo de sua importância.

Embora ainda seja necessário ampliar o leque de atores sociais e políticos entrevistados para evidenciar suas percepções sobre as questões climáticas e analisar um volume 
maior de instrumentos de políticas públicas incidentes direta e indiretamente sobre as mudanças climáticas, o trabalho já apresenta a referida triangulação como método de análise consistente e reforça os estudos de municípios de médio porte.

\section{BIBLIOGRAFIA}

AMORIM, M.C.C.T., DUBREUIL, V., QUENOL, H., SANT'ANNA NETO, J.L.. Características das ilhas de calor em cidades de porte médio : exemplos de Presidente Prudente (Brasil) e Rennes (França). Confins. Paris, núm. 7, 1-16. 2009. <http://journals.openedition.org/confins/6070 ; DOI : https:// doi.org/10.4000/confins.6070>.

AMORIM, Margarete Cristiane de Costa Trindade. «Ilhas de calor urbano em cidades de pequeno e médio porte no Brasil e o contexto das mudanças climáticas», Confins [Online], 46 | 2020.

AMORIM, Margarete Cristiane de Costa Trindade; DUBREUIL, Vincent; QUENOL, Hervé; SANT 'ANA NETO, João Lima. «Características das ilhas de calor em cidades de porte médio: exemplos de Presidente Prudente (Brasil) e Rennes (França)», Confins [Online], 7 | 2009.

BRYSON, R.A., ROSS, J.E.. The climate of the city. Urbanization and environment, Belmont: Duxbury Press. 1972.

Câmara Municipal de Jacareí. Lei no 4847, de 07 de janeiro de 2005. Dispõe sobre uso, ocupação e urbanização do solo do município de Jacareí. 2005.

CALDAS, Eduardo de Lima; MASSARDIER, Gilles. «La climatisation des politiques dans un contexte de fragmentation et sectorialisation des agendas et de la mise en œuvre des instruments», Confins [Online], $46 \mid 2020$.

CARDOSO, R.S., DORIGON, L.P., TEIXEIRA, D.C.F., AMORIM, M.C.C.T.. Assessment of urban heat islands in small-and mid-sized cities in Brazil. Climate, núm. 5, 14-26. 2017. <https:// www.mdpi.com/2225-1154/5/1/14 https://doi.org/10.3390/cli5010014>

CHECCO, G. B., CALDAS, E. L. Governos subnacionais e a Política de Mudanças Climáticas de São Paulo: uma análise a partir da multiposição dos atores na cidade de São Paulo, Confins [Online], 39 | 2019. <http://journals.openedition.org/confins/18818; DOI: https://doi.org/10.4000/confins. $18818>$

CORBURN J.. Cities, Climate Change and Urban Heat Island Mitigation : Localising Global Environment Science. Urban Studies, v. 46, núm. 2, 413-427. 2009. <https://journals.sagepub.com/ doi/10.1177/0042098008099361>.

ETZIONI, A. Organizações Modernas. São Paulo: Atlas, 1972.

FARIA, J.L.G., MONTEIRO, E.A., FISCH, S.T.V.. Arborização de vias públicas do município de Jacareí - SP. Revista SBAU, v. 2, núm. 4, 20-33. 2007. <http://silvaurba.esalq.usp.br/revsbau/ artigos_cientificos/artigo29.pdf>.

GOMES, C., RESCHILIAN, P.R., UEHARA, A.Y. Perspectivas do planejamento regional do Vale do Paraíba e Litoral Norte: marcos históricos e institucionalização da região metropolitana no Plano 
de Ação da Macrometrópole paulista. URBE, Revista Brasileira de Gestão Urbana (Brazilian Journal of Urban Management), 10(1), pp. 154-171. 2018. <https://doi.org/10.1590/2175-3369.010.001.ao07>.

IBGE. Instituto Brasileiro de Geografia e Estatística. Perfil dos municípios brasileiros. IBGE, Coordenação de População e Indicadores Sociais, Rio de Janeiro. 2017.

HOOD, C. The tools of government. Chatham: Chatham House, 1986.

LASCOUMES, P.; LE GALÈS, P. A ação pública abordada pelos seus instrumentos. Revista Pós Ciências Sociais, São Luís, v. 9, n. 18, p. 19-44, 2012.

LANDSBERG, M.E.. The urban climate, New York, Academia Press. 1981.

LOMBARDO, M.. A. Ilha de calor nas metrópoles: o exemplo de São Paulo, São Paulo, Hucitec. 1985.

LUCENA, A. J. de. Notas conceituais e metodológicas em clima urbano e ilhas de calor. Revista Continentes (UFRRJ), ano 2, núm. .2, pp. 28-56. 2013. < http://www.revistacontinentes.com.br/ continentes/index.php/continentes/article/view/17>.

MELLO-THÉRY, NELI APARECIDA DE ; DE LIMA CALDAS, EDUARDO ; FUNATSU, BEATRIZ M. ; ARVOR, DAMIEN ; DUBREUIL, VINCENT . Climate Change and Public Policies in the Brazilian Amazon State of Mato Grosso: Perceptions and Challenges. Sustainability, v. 12, p. 5093, 2020.

MENDONÇA, F.A.. O clima e o planejamento urbano decidades de porte médio e pequeno. Proposição metodológica para estudo e sua aplicação à cidade de Londrina/PR. Tese de doutorado, Universidade de São Paulo. São Paulo 1995.

MENDONÇA, F.A.. Clima e planejamento urbano em Londrina-Preposição metodológica e de intervenção urbana a partir do estudo do campo térmico. In: Clima Urbano, Monteiro, C.A.F., Mendonça, F. (eds.), São Paulo, Editora Contexto, 93-120. 2003.

MENDONÇA, F.A.. La connaissance du climat au Brésil : entre le vernaculaire et le scientifique, Confins [Online], Paris, núm. 15, 2012. <http://confins.revues.org/7610. DOI : 10.4000/confins. 7610. 2012>.

MONTEIRO, C.A.F.. Teoria e Clima Urbano. São Paulo, IGEOG. Universidade de São Paulo. 1976.

OKE, T. R. Boundary Layer Climate. Second edition, London, Methuen \& Co. 1987.

PERARD, J.. Risques climatiques et espace vécu dans le domaine intertropical. Le climat, l'eau et les hommes - Ouvrage en l'honneur de Jean Mounier. Rennes, Presse Universitaire de Rennes (PUR), p. 105-111. 1997

PORANGABA, Gislene Figueiredo Ortiz; AMORIM, Margarete Cristiane de Costa Trindade. «Análise de ilhas de calor diagnosticas por meio de transectos móveis em Assis, Cândido Mota, Maracaí e Tarumã (SP)», Confins [Online], 33 | 2017.

REVI A. et al.. Urban areas. In: Climate Change 2014: Impacts, Adaptation, and Vulnerability. Part A : Global and Sectoral Aspects. Contribution of Working Group II to the Fifth Assessment Report of the Intergovernmental Panel on Climate Change, Field C.B. et al. (eds.), New York, Cambridge University Press, Cambridge, 535-612. 2014.

RIBEIRO, W.C.. Impactos das mudanças climáticas em cidades no Brasil. Parcerias Estratégicas, v. 13, núm. 27, 297-321. 2008.

RODRIGUES, M.L.R; MALHEIROS, T.F; FERNANDES, V; DAROS, T.D. A Percepção Ambiental Como Instrumento de Apoio na Gestão e na Formulação de Políticas Públicas Ambientais. Saude Soc. São Paulo, v. 21, supl. 3, p. 96-110. 2012. <https://doi.org/10.1590/S0104-12902012000700009>. 
SALAMON, L. The tools of government: a guide to the new governance. New York: Oxford University Press, 2002,

TEIXEIRA, D.C.F., AMORIM, M.C.C.T.. O estudo da ilha de calor em cidade de pequeno porte: algumas contribuições. Sociedade \& Natureza, 30(2),186-209. 2018. <<http://www.seer.ufu.br/ index.php/sociedadenatureza/article/view/40997. https://doi.org/10.14393/SN-v30n2-2018-9>.

VOOGT, J.A.. Urban Heat Islands: Causes and consequences of global environmental change. Encyclopedia of Global Environmental Change, 3, 660-666. 2002.

YNOUE, R.Y.. Rapport finale du Project FAPESP-CONDEPHAAT "Patrimônio cultural do Vale Histórico Paulista: análise da vulnerabilidade às mudanças climáticas". 2014.

\section{RESUMOS}

Mudanças climáticas têm sido tema prioritário para alguns governos. No caso brasileiro, mais frequente em políticas estaduais e mesmo municipais que no âmbito nacional. Alguns municípios "engatinham" na definição de ações, algumas vezes, incluídas em planos ou programas setoriais, sem dar-lhes prioridade, embora possam representar soluções. Muitas vezes faltam-lhes informações. Para suprir o município de informações, foram instalados medidores meteorológicos na cidade de Jacareí-SP, cujos dados permitiram a análise do quadro climático. Paralelamente a isso, analisou-se a atuação governamental quanto a ações voltadas para a redução do stress ao calor. Do ponto de vista teórico-metodológico, o artigo contribui para articular noções conceituais sobre instrumentos governamentais, a ilha de calor urbana e percepção quanto à questão climática.

Climate change has been a priority issue for some governments. In the Brazilian case, this is more frequent in state and even municipal policies and less at the federal level. Some municipalities are in the process of defining actions, sometimes included in sector plans or programs, without giving them priority, although they may represent solutions. They often lack information. In this context, meteorological stations were installed in the city of Jacareí, whose data allowed the analysis of the climatic situation. In parallel to this, the government's performance was analyzed in relation to actions aimed at reducing urban heat. From a theoretical and methodological point of view, the article contributes to articulate conceptual notions about government instruments, heat islands and perception regarding the climate issue.

Le changement climatique est une question prioritaire pour certains gouvernements. Dans le cas brésilien, cela est plus fréquent dans les politiques des états et des communes et moins au niveau fédéral. Certaines communes sont en train de définir des actions, parfois inscrites dans des plans ou programmes sectoriels, sans leur donner la priorité, même si elles peuvent représenter des solutions. Ils manquent souvent d'informations. Dans ce contexte, des stations météorologiques ont été installées dans la ville de Jacareí, dont les données ont permis l'analyse de la situation climatique. Parallèlement, la performance du gouvernement a été analysée par rapport aux actions visant à réduire la chaleur urbaine. D'un point de vue théorique et méthodologique, l'article contribue à articuler des notions conceptuelles sur les instruments gouvernementaux, les îlots de chaleur et la perception de la question climatique.

El cambio climático ha sido un tema prioritario para algunos gobiernos. En el caso brasileño, es más frecuente en las políticas estatales y municipales, y menos frecuente en el ámbito nacional. Algunos municipios se "arrastran" en la definición de acciones, a veces incluidas en planes o programas sectoriales, sin darles prioridad, aunque puedan representar soluciones. A menudo 
carecen de información. Para dotar de información al municipio, se instalaron estaciones meteorológicas en la ciudad de Jacareí-SP, cuyos datos permitieron el análisis de la situación climática. Paralelamente, se analizó el desempeño del gobierno en relación a las acciones encaminadas a reducir el estrés por calor. Desde un punto de vista teórico-metodológico, el artículo contribuye para articular nociones conceptuales sobre instrumentos gubernamentales, islas de calor y percepción del tema climático.

\section{ÍNDICE}

Mots-clés: changement climatique, action gouvernementale, contexte local d'action publique, îlots de chaleur, Jacareí-SP (Brésil)

Palavras-chave: mudanças climáticas, atuação governamental, ação pública, ilhas de calor, Jacareí-SP (Brasil)

Keywords: climate change, government action, public action local context, heat islands, JacareíSP (Brasil)

Palabras claves: cambio climático, acción gubernamental, contexto local de acción pública, islas del calor, Jacareí-SP (Brasil)

\section{AUTORES}

\section{NELI APARECIDA DE MELLO-THÉRY (IN MEMORIAM)}

Universidade de São Paulo, Escola de Artes, Ciências e Humanidades. Email: namello@usp.br

\section{ANDREA CAVICCHIOLI}

Universidade de São Paulo, Escola de Artes, Ciências e Humanidades. Email: andrecav@usp.br

\section{EDUARDO DE LIMA CALDAS}

Universidade de São Paulo, Escola de Artes, Ciências e Humanidades. Email:

eduardocaldas@usp.br 